\title{
PENGARUH KUALITAS PRODUK DAN KUALITAS PELAYANAN TERHADAP KEPUTUSAN PENGGUNA INDIHOME DI KARAWANG
}

\author{
Mega Naliyah Syahfitri ${ }^{1}$ Danang Kusnanto ${ }^{2}$
}

\begin{tabular}{|c|c|}
\hline Article history: & Abstract \\
\hline $\begin{array}{l}\text { Submitted: } \\
\text { 16 Maret } 2021 \\
\text { Revised: } \\
\text { 12 April } 2021 \\
\text { Accepted: } \\
\text { 13 April } 2021\end{array}$ & $\begin{array}{l}\text { This study aims to determine how the influence of product quality and service } \\
\text { quality on IndiHome user decisions in Karawang. The population in this } \\
\text { study were all IndiHome users in Karawang, with a total sample size of } 100 \\
\text { respondents with the sampling method using snowball sampling. The data } \\
\text { was collected by distributing questionnaires online via Google Form. This } \\
\text { research was done by using verification and descripstion method were to } \\
\text { know, to explain, to analyze and to do the hypothesis testing, and to make a } \\
\text { conclusion and suggestion. The results of this study indicate that Product } \\
\text { Quality has a positive and significant effect on IndiHome User Decisions in }\end{array}$ \\
\hline $\begin{array}{l}\qquad \text { Keywords: } \\
\text { Product Quality; } \\
\text { Service Quality; } \\
\text { User Decision; }\end{array}$ & $\begin{array}{l}\text { Karawang, and Service Quality has a positive and significant effect on } \\
\text { IndiHome User Decisions in Karawang. }\end{array}$ \\
\hline Kata Kunci: & Abstrak \\
\hline $\begin{array}{l}\text { Kualitas Produk; } \\
\text { Kualitas Pelayanan; } \\
\text { Keputusan Pengguna; }\end{array}$ & $\begin{array}{l}\text { Penelitian ini bertujuan untuk mengetahui bagaimana pengaruh kualitas } \\
\text { produk dan kualitas pelayanan terhadap keputusan pengguna IndiHome di } \\
\text { Karawang. Populasi dalam penelitian ini adalah seluruh pengguna IndiHome }\end{array}$ \\
\hline $\begin{array}{l}\quad \text { Koresponding: } \\
\text { Fakultas Ekonomi, } \\
\text { Universitas Singaperbangsa } \\
\text { Karawang, Jawa Barat, } \\
\text { Indonesia } \\
\text { Email: } \\
\text { meganaliyah16@gmail.com }\end{array}$ & $\begin{array}{l}\text { di Karawang, dengan jumlah sampel yang didapat sebanyak } 100 \text { responden } \\
\text { dengan metode pengambilan sampel menggunakan snowball sampling. } \\
\text { Pengumpulan data dilakukan dengan menyebarkan angket secara online } \\
\text { melalui Google Form. Penelitian ini dilakukan dengan menggunakan metode } \\
\text { deskriptif dan verifikatif yaitu mengetahui, menjelaskan, menganalisis dan } \\
\text { melakukan pengujian hipotesis, serta membuat kesimpulan dan saran. Hasil } \\
\text { penelitian ini menunjukkan bahwa Kualitas Produk berpengaruh positf dan } \\
\text { signifikan terhadap Keputusan Pengguna IndiHome di Karawang, dan } \\
\text { Kualitas Pelayanan berpengaruh positif dan signifikan terhadap Keputusan } \\
\text { Pengguna IndiHome di Karawang }\end{array}$ \\
\hline
\end{tabular}

Fakultas Ekonomi, Universitas Singaperbangsa Karawang, Jawa Barat, Indonesia ${ }^{2}$

Email: danang.kusnanto@fe.unsika.ac.id 


\section{PENDAHULUAN}

Perkembangan teknologi informasi dan komunikasi yang semakin pesat, saat ini sudah menjadi ketergantungan aktivitas manusia sebagai alat penunjang kelancaran tugas publik bahkan sebagai alat pelengkap hiburan bagi manusia. Perkembangan teknologi informasi dan komunikasi salah satunya adalah internet. kebutuhan pengguna internet yang semakin pesat dilihat dari adanya virus corona yang telah menginfeksi dunia pada awal tahun 2020. Pertumbuhan pengguna internet di Indonesia semakin meningkat yang salah satu penyebab peningkatan tersebut dikarenakan adanya pandemi corona, maka terjadinya peningkatan permintaan layanan internet di kala di rumah saja Work From Home (WFH). Adanya permintaan, maka masyarakat harus mengeluarkan sejumlah uang untuk mendapatkan kecepatan internet yang baik juga pelayanan yang responsive. Maka dari itu, banyak perusahaan provider yang menawarkan layanan jasa internet.

Salah satu perusahaan yang menawarkan layanan jasa internet yaitu PT Telkom Indonesia (Persero), Tbk dikenal dengan nama Telkom yang merupakan perusahaan Badan Usaha Milik Negara (BUMN) yang bergerak di bidang jasa teknologi informasi dan komunikasi (TIK) dan jaringan telekomunikasi di Indonesia. Telkom memiliki produk internet yang pertama bernama Speedy, yang sekarang di rebranding menjadi IndiHome diluncurkan pada Januari 2015 dan dikatakan dapat menggunakan teknologi fiber optik untuk menyediakan koneksi internet yang lebih stabil. IndiHome atau Indonesia Digital Home menyediakan berupa paket layanan digital terkemuka menggunakan teknologi fiber optik untuk menyediakan layanan Triple Play termasuk Internet Rumah (Fixed Broadband Internet), Telepon Rumah (Fixed Phone) dan TV Interaktif (UseeTV). Keunggulan layanan internet IndiHome memiliki teknologi fiber optik yang berkecepatan tinggi, jaringan fiber optik dapat mengirimkan data hingga 100 Mbps, jaringan fiber optic mampu jauh lebih stabil, dalam kondisi cuaca apapun (seperti petir dan gangguan elektromagnetik) memiliki ketahanan yang lebih tinggi, serta teknologi fiber optic transmisi data paling canggih dan terbaru yang digunakan dalam layanan fixed broadband.

Menurut data survei Asosiasi Penyelenggara Jasa Internet Indonesia (APJII, 2018), produk IndiHome menduduki peringkat pertama dengan konsumen paling banyak di Indonesia dengan persentase sebesar $8,7 \%$, peringkat selanjutnya diikuti oleh First Media dengan persentase sebesar $1,7 \%$, dan ketiga perusahaan fixed broadband memiliki persentase yang sama sebesar 0,4\% oleh Biznet Network, MyRepublic dan MNC Play. Adapun pertumbuhan Pelanggan IndiHome di Indonesia 2017-2019, pelanggan IndiHome di Indonesia mengalami peningkatan setiap tahunnya, dengan adanya kenaikan pelanggan IndiHome karena dilakukannya strategi pemasaran yang sudah ditetapkan sepanjang tahun 2019, yang akan terus mendorong pelanggan untuk membeli layanan tambahan seperti peningkatan kecepatan, tambahan set-topbox, dan ransel mikro langganan (TelkomIndonesia, 2019). 
Salah satunya pada PT. Telkom Witel Karawang yang mendapatkan lonjakan pelanggan baru IndiHome setiap bulannya. General Manager PT. Telkom Witel Karawang Sonny Hidayat menyampaikan bahwa lonjakan pelanggan baru IndiHome dimulai sejak Februari sampai bulan Juli dengan masih menunjukkan rata-rata 4000 pelanggan baru per bulannya. Jumlah tersebut dua kali lipat dari jumlah sekitar 1000 hingga 2000 pengguna baru per bulan sebelum pandemi, dan pertumbuhan pengguna baru mencapai puncaknya di bulan Mei (Raka, 2020).

Banyaknya jumlah pelanggan IndiHome tidak membuat reputasi Telkom Indihome itu selalu baik. Tahun ke tahun sejumlah pelanggan IndiHome memberikan keluhan kepada call center Telkom IndiHome 147. Salah satu pelanggan mengatakan bahwa pelayanan IndiHome tidak sigap dalam hal menjawab (unresponsiveness) keluhan pelanggan dan tidak adanya pertanggung jawaban dengan tidak memberikan hak-hak konsumen kepada pelanggan IndiHome (Mediakonsumen.com, 2020). Gangguan yang sering dihadapkan oleh sejumlah pengguna IndiHome yaitu gangguan yang didominasi pada koneksi internet yang dilaporkan lamban dan bahkan terputus koneksi Wi-Fi IndiHome di ponsel pengguna (Pertiwi, 2020), dan gangguan jaringan IndiHome yang tidak bisa mengakses layanan video call melalui aplikasi Zoom (Kristo, 2020). Dari beberapa keluhan yang disampaikan pengguna IndiHome sangat berdampak bagi calon konsumen yang sedang mencari informasi mengenai IndiHome sebelum memutuskan untuk membeli dan menggunakannya, tentu dari kualitas produk dan kualitas pelayanan IndiHome yang kurang baik sangat berpengaruh bagi calon konsumen untuk ke tahap keputusan pembelian. Secara aktual, melakukan pembelian produk dalam hal ini menggunakan produk IndiHome.

Keputusan pembelian dalam menggunakan produk IndiHome dipengaruhi oleh beberapa faktor salah satunya adalah kualitas produk. Menurut Kotler \& Keller (2012) hubungan antara kualitas produk dan keputusan pembelian adalah konsumen tertarik untuk membeli produk yang disediakan oleh perusahaan. Kotler \& Armstong (2018) menyatakan bahwa "Product quality is the characteristics of a product or service that bear on its ability to satisfy stated or implied customer needs" atau "kualitas produk adalah karakteristik dari produk atau jasa yang bergantung pada kemampuannya untuk memenuhi kebutuhan pelanggan yang tersurat maupun tersirat". Sedangkan menurut Mowen \& Minor (2012) Kualitas produk adalah keseluruhan proses evaluasi bagi pelanggan untuk meningkatkan kinerja produk atau jasa. Menurut penelitian yang dilakukan oleh Daulay (2017) kualitas produk memiliki pengaruh positif signifikan terhadap keputusan pembelian. Sedangkan menurut penelitian yang dilakukan oleh Rumondor (2017) kualitas produk berpengaruh positif namun tidak signifikan terhadap keputusan pembelian. Adapun perbedaan penelitian yang dilakukan oleh Mertayasa \& Giantari (2020) kualitas produk berpengaruh positif dan signifikan terhadap kepuasan pelanggan dan komunikasi word of mouth. Sehingga dalam penelitian ini 
bertujuan untuk mengetahui kualitas produk terhadap keputusan pengguna, sesuai dengan teori Kotler \& Armstong (2018) bahwa semakin baik kualitas produk yang dihasilkan maka kesempatan konsumen untuk melakukan keputusan penggunaan semakin tinggi.

Selain kualitas produk, kualitas pelayanan juga merupakan timbangan pokok dalam keputusan pembelian, pernyataan tersebut sepaham dengan hasil penelitian Kodu (2013) menyatakan adanya pelayanan yang berkualitas akan mendorong konsumen untuk mengambil keputusan pembelian. Selain itu, pelayanan yang berkualitas juga dapat mendorong konsumen untuk membangun hubungan yang kuat dengan perusahaan. Menurut Tjiptono dalam Sunyoto (2012) kualitas atau mutu dalam industri jasa adalah produk atau jasa yang dinyatakan dalam ukuran umum tempat produk diproduksi, dan penyampaiannya setidaknya sama dengan yang diingkan dan diharapkan konsumen. Kualitas pelayanan berpengaruh positif dan signifikan terhadap keputusan pembelian (Weenas, 2013), sedangkan menurut Nasution (2017) kualitas pelayanan tidak memiliki pengaruh signifikan terhadap keputusan pembelian. Adapun perbedaan penelitian yang dilakukan oleh Abdul (2017) mengenai kualitas pelayanan yang memiliki hasil penelitian kualitas pelayanan dapat berpengaruh secara signifikan dan positif terhadap kepuasan, kepercayaan dan loyalitas pelanggan, penelitian tersebut sesuai dengan teori Kotler yang dikutip oleh Arief (2020) bahwa terdapat tiga faktor penentu kualitas pelayanan yaitu process, physical evidence dan people yang menentukan perilaku keputusan pembelian menjadi pelanggan yang puas dan membentuk pelanggan yang loyal. Berdasarkan perbedaan hasil penelitian yang dilakukan Weenas (2013); Nasution (2017); Abdul (2017) maka, penelitian ini ingin mengetahui bagaimana kualitas pelayanan berpengaruh terhadap keputusan pengguna IndiHome Karawang.

Berdasarkan telaah dan kajian penelitian terdahulu, maka dapat disusun hipotesis sebagai berikut:

$\mathrm{H}_{1}$ : Terdapat pengaruh Kualitas Produk terhadap Keputusan Penggunaan IndiHome di Karawang.

$\mathrm{H}_{2}$ : Terdapat pengaruh Kualitas Pelayanan terhadap Keputusan Pengggunaan IndiHome di Karawang.

$\mathrm{H}_{3}$ : Terdapat pengaruh Kualitas Produk dan Kualitas Pelayanan terhadap Keputusan Penggunaan IndiHome di Karawang.

\section{METODE PENELITIAN}

Metode penelitian yang digunakan dalam penelitian ini adalah penelitian kuantitatif, dan penelitian yang dilakukan secara langsung melibatkan objek yang diteliti untuk memahami dan menjelaskan peristiwa serta memahami maknanya, teknik analisis data menggunakan penelitian deskriptif dan penelitian verifikatif.

Populasi dalam penelitian ini diambil dari pengguna IndiHome Karawang, pengambilan sampel diambil menggunakan teknik snowball sampling. Snowball sampling adalah sebagai teknik penentuan sampel jumlah awal sedikit, kemudian sampel tersebut diharuskan untuk memilih teman 
yang akan dijadikan sampel, begitu seterusnya, agar jumlah sampel semakin bertambah seperti semakin lama bola salju menggelinding maka semakin besar sampelnya (Sugiyono, 2014). Responden diminta melakukan pengisian angket secara online menggunakan Google Form, dan ditanyakan kembali siapa saja yang di ketahui yang menggunakan IndiHome di Karawang, sehingga sampel yang diambil dalam penelitian ini mendapatkan jumlah sebesar 100 responden pengguna IndiHome di Karawang. Selanjutnya pengumpulan data akan di ukur dengan pengukuran teknik skala likert.

Metode analisis yang digunakan pada penelitian ini menggunakan Uji validitas, Uji realibilitas, Uji asumsi klasik (terdiri dari uji normalitas, uji multikolinearitas, uji heteroskedastisitas); Uji regresi linier berganda; Uji korelasi berganda; Uji koefisien determinasi; Uji parsial dan Uji Simultan.

Dalam penelitian ini terdapat variabel independen (bebas), dan variabel dependen (terikat). Variabel independen dalam penelitian ini yaitu Kualitas Produk $\left(\mathrm{X}_{1}\right)$ dan Kualitas Pelayanan $\left(\mathrm{X}_{2}\right)$, variabel dependen dalam penelitian ini adalah Keputusan Pengguna (Y). Berikut merupakan indikatorindikator tiap variabel yang dapat diukur disajikan pada Tabel 1 .

Tabel 1.

Instrumen Penelitian

\begin{tabular}{|c|c|c|}
\hline Variabel & Sub Variabel & Indikator \\
\hline \multirow{6}{*}{ Kualitas Produk } & Kinerja & Kinerja layanan internet IndiHome \\
\hline & Fitur & IndiHome media internet browsing dan TV online \\
\hline & Keandalan & Jaringan baik di segala cuaca \\
\hline & Kesesuaian & Kualitas sesuai yang ditawarkan \\
\hline & Daya tahan & Mutu IndiHome sesuai harga \\
\hline & Estetika & Produk IndiHome dirancang modern \\
\hline \multirow{5}{*}{ Kualitas Pelayanan } & Bukti fisik & $\begin{array}{l}\text { Peralatan yang mendukung } \\
\text { Petugas rapih dan bersih }\end{array}$ \\
\hline & Kehandalan & $\begin{array}{l}\text { MyIndihome melayani konsumen } \\
\text { Keluhan dapat diselesaikan }\end{array}$ \\
\hline & Daya Tanggap & $\begin{array}{l}\text { Daya tanggap baik dan cepat } \\
\text { Pelayanan ramah dan santun }\end{array}$ \\
\hline & Jaminan & $\begin{array}{l}\text { Kecepatan dan ketepatan waktu } \\
\text { Keterampilan dan pengetahuan baik }\end{array}$ \\
\hline & Empati & $\begin{array}{l}\text { Melayani tanpa memandang status sosial } \\
\text { Perhatian kepada konsumen }\end{array}$ \\
\hline \multirow{2}{*}{ Keputusan Pengguna } & Kebutuhan akan pengenalan & $\begin{array}{l}\text { Sesuai kebutuhan } \\
\text { Kualitas yang dijanjikan }\end{array}$ \\
\hline & Evaluasian alternatif & $\begin{array}{l}\text { Evaluasi provider lain } \\
\text { Evaluasi perkembangan IndiHome }\end{array}$ \\
\hline \multirow[b]{2}{*}{ Keputusan Pengguna } & Pembelian & Hasil saran teman dan keluarga \\
\hline & Perilaku pasca pembelian & $\begin{array}{l}\text { Mereferensikan orang lain } \\
\text { Kepuasan }\end{array}$ \\
\hline
\end{tabular}




\section{HASIL DAN PEMBAHASAN}

Terdapat profil responden pengguna IndiHome dari data yang di ambil yaitu sebesar 100 responden yang telah ikut berpartisipasi melalui pengisian kuesioner (angket) penelitian beserta karakteristik karakteristik responden berupa jenis kelamin, usia dan pendidikan terakhir yang dapat dilihat pada Tabel 2 .

Tabel 2.

Karakteristik Sampel Responden Pengguna IndiHome

\begin{tabular}{ccccc}
\hline \multicolumn{2}{c}{ No Karakteristik Klasifikasi } & $\begin{array}{c}\text { Jumlah } \\
\text { Responden }\end{array}$ & $\begin{array}{c}\text { Persentase } \\
(\mathbf{\%})\end{array}$ \\
\hline 1. & Jenis Kelamin & Laki-laki & 22 & 22 \\
& & Perempuan & 78 & 78 \\
\hline 2. & Usia & $<20$ thn & 7 & 7 \\
& & $21-40$ thn & 93 & 93 \\
\hline \multirow{2}{*}{ 3. } & Pendidikan & SMA & 62 & 62 \\
& Terakhir & SMA & 2 & 2 \\
& & SMK & 2 & 8 \\
& & Diploma & 8 & 25 \\
& & S1 & 25 & 3 \\
\hline & S2/S3 & 3 & \\
\hline
\end{tabular}

Sumber : Data diolah, 2021

Pada Tabel 2 menunjukkan bahwa responden dengan karakteristik jenis kelamin laki-laki sebanyak 22 orang dengan persentase sebesar 22\%, sedangkan perempuan sebanyak 78 orang dengan persentase sebesar $78 \%$. Karakteristik responden yang berusia kurang dari 20 tahun sebanyak 7 orang dengan persentase $7 \%$ dan responden yang berusia 21-40 tahun sebanyak 93 orang dengan persentase $93 \%$. Karakteristik responden berdasarkan pendidikan terakhir pada SMA sebanyak 62 orang dengan persentase $62 \%$, pada SMK sebanyak 2 orang dengan persentase $2 \%$,
Diploma sebanyak 8 orang dengan persentase $8 \%$, S1 sebanyak 25 orang dengan persentase $25 \%$, dan S2/S3 sebanyak 3 orang dengan persentase $3 \%$.

Agar hasil analisis data pada penelitian ini dapat represiantive dan dapat dipercaya, maka perlu dilakukan uji validitas untuk masing-masing indikator sebagai item pernyataan, pengujian validitas dapat dilihat pada Tabel 3.

Tabel 3.

Hasil Uji Validitas Kualitas Produk ( $\left.\mathbf{X}_{1}\right)$

\begin{tabular}{|c|c|c|c|}
\hline $\begin{array}{c}\text { Item } \\
\text { Pernyataan }\end{array}$ & $\begin{array}{c}\text { Koefisien } \\
\text { Korelasi }\end{array}$ & Kriteria & Keterangan \\
\hline $\begin{array}{l}\text { Kinerja } \\
\text { layanan intenet } \\
\text { IndiHome }\end{array}$ & 0,666 & 0,3 & Valid \\
\hline $\begin{array}{l}\text { IndiHome } \\
\text { media internet } \\
\text { dan TV online }\end{array}$ & 0,539 & 0,3 & Valid \\
\hline $\begin{array}{l}\text { Jaringan baik } \\
\text { di segala cuaca }\end{array}$ & 0,573 & 0,3 & Valid \\
\hline $\begin{array}{l}\text { Kualitas sesuai } \\
\text { yang } \\
\text { ditawarkan }\end{array}$ & 0,696 & 0,3 & Valid \\
\hline $\begin{array}{l}\text { Mutu } \\
\text { IndiHome } \\
\text { sesuai harga }\end{array}$ & 0,820 & 0,3 & Valid \\
\hline $\begin{array}{l}\text { Produk } \\
\text { dirancang } \\
\text { modern }\end{array}$ & 0,814 & 0,3 & Valid \\
\hline
\end{tabular}

Sumber : Data diolah, 2021

Berdasarkan Tabel 3. Uji validitas, seluruh Indikator sebagai item pernyataan penelitian pada variabel Kualitas Produk $\left(\mathrm{X}_{1}\right)$ menunjukkan valid, karena koefisien korelasi memilki nilai diatas 0,30 maka dapat disimpulkan bahwa data yang diperoleh dari semua pernyataan merupakan data yang valid. 
Pengaruh Kualitas Produk dan Kualitas Pelayanan Terhadap...

Mega Naliyah Syahfitri \& Danang Kusnanto

Tabel 4.

Hasil Uji Validitas Kualitas Pelayanan $\left(\mathbf{X}_{2}\right)$

\begin{tabular}{lccc}
\hline \multicolumn{1}{c}{$\begin{array}{c}\text { Item } \\
\text { Pernyataan }\end{array}$} & $\begin{array}{c}\text { Koefisien } \\
\text { Korelasi }\end{array}$ & Kriteria & Keterangan \\
\hline $\begin{array}{l}\text { Peralatan } \\
\text { yang } \\
\text { mendukung }\end{array}$ & 0,765 & 0,3 & Valid \\
\hline $\begin{array}{l}\text { Petugas rapih } \\
\text { dan bersih }\end{array}$ & 0,705 & 0,3 & Valid \\
\hline $\begin{array}{l}\text { MyIndihome } \\
\text { melayani } \\
\text { konsumen }\end{array}$ & 0,718 & 0,3 & Valid \\
\hline $\begin{array}{l}\text { Keluhan } \\
\text { dapat }\end{array}$ & 0,716 & 0,3 & Valid \\
diselesaikan & 0,843 & 0,3 & Valid \\
\hline $\begin{array}{l}\text { Daya tanggap } \\
\text { baik dan } \\
\text { cepat }\end{array}$ & 0,801 & 0,3 & Valid \\
\hline $\begin{array}{l}\text { Pelayanan } \\
\text { ramah dan } \\
\text { santun }\end{array}$ & 0,830 & 0,3 & Valid \\
\hline $\begin{array}{l}\text { Kecepatan } \\
\text { dan ketepatan } \\
\text { waktu }\end{array}$ & 0,856 & 0,3 & Valid \\
\hline $\begin{array}{l}\text { Keterampilan } \\
\text { dan } \\
\text { pengetahuan } \\
\text { baik }\end{array}$ & 0,816 & 0,3 & Valid \\
\hline $\begin{array}{l}\text { Melayani } \\
\text { kanpa } \\
\text { memandandang } \\
\text { status sosial }\end{array}$ & 0,870 & 0,3 & \\
\hline $\begin{array}{l}\text { Perhatian } \\
\text { kumber: Data }\end{array}$ & & & \\
\hline
\end{tabular}

Sumber : Data diolah, 2021

Berdasarkan Tabel 4. Uji validitas, seluruh Indikator sebagai item pernyataan penelitian pada variabel Kualitas Pelayanan $\left(\mathrm{X}_{2}\right)$ menunjukkan valid, karena koefisien korelasi memilki nilai diatas 0,30 maka dapat disimpulkan bahwa data yang diperoleh dari semua pernyataan merupakan data valid.
Tabel 5.

Hasil Uji Validitas Keputusan Pengguna (Y)

\begin{tabular}{lccc}
\hline \multicolumn{1}{c}{$\begin{array}{c}\text { Item } \\
\text { Pernyataan }\end{array}$} & $\begin{array}{c}\text { Koefisien } \\
\text { Korelasi }\end{array}$ & Kriteria & Keterangan \\
\hline $\begin{array}{l}\text { Sesuai } \\
\text { kebutuhan }\end{array}$ & 0,664 & 0,3 & Valid \\
\hline $\begin{array}{l}\text { Kualitas } \\
\text { yang } \\
\text { dijanjikan }\end{array}$ & 0,739 & 0,3 & Valid \\
\hline $\begin{array}{l}\text { Evaluasi } \\
\text { provider lain }\end{array}$ & 0,780 & 0,3 & Valid \\
\hline $\begin{array}{l}\text { Evaluasi } \\
\text { perkembang } \\
\text { an IndiHome }\end{array}$ & 0,629 & 0,3 & Valid \\
\hline $\begin{array}{l}\text { Hasil saran } \\
\text { teman dan } \\
\text { keluarga }\end{array}$ & 0,610 & 0,3 & Valid \\
\hline $\begin{array}{l}\text { Mereferensi } \\
\text { kan orang } \\
\text { lain }\end{array}$ & 0,757 & 0,3 & Valid \\
\hline $\begin{array}{l}\text { Kepuasan } \\
\text { Sumber: }\end{array}$ & 0,745 & 0,3 & Valid \\
\hline
\end{tabular}

Sumber : Data diolah, 2021

Berdasarkan Tabel 5. Uji validitas, seluruh Indikator sebagai item pernyataan penelitian pada variabel Keputusan Pengguna (Y) menunjukkan valid, karena koefisien korelasi memilki nilai diatas 0,30 maka dapat disimpulkan bahwa data yang diperoleh dari semua pernyataan merupakan data valid.

Tabel 6.

Hasil Uji Reliabilitas

\begin{tabular}{lccc}
\hline \multicolumn{1}{c}{ Variabel } & r hitung & r kritis & Kriteria \\
\hline $\begin{array}{l}\text { Kualitas Produk } \\
\left(\mathrm{X}_{1}\right)\end{array}$ & 0,765 & 0,6 & Reliabel \\
$\begin{array}{l}\text { Kualitas Pelayanan } \\
\left(\mathrm{X}_{2}\right)\end{array}$ & 0,933 & 0,6 & Reliabel \\
$\begin{array}{l}\text { Keputusan } \\
\text { Pengguna (Y) }\end{array}$ & 0,828 & 0,6 & Reliabel \\
\hline Sumber : Data diolah, 2021 & &
\end{tabular}

Buletin Studi Ekonomi 
Berdasarkan Tabel 6. Hasil uji reliabilitas tiap variabel memiliki nilai $r$ hitung > r kritis $(0,6)$ artinya, semua variabel dinyatakan reliabel. Maka, dapat diketahui bahwa kualitas produk memiliki nilai $r$ hitung sebesar 0,765, kualitas pelayanan sebesar 0,933, dan keputusan pengguna sebesar 0,828 .

Tabel 7.

Hasil Uji Normalitas

\begin{tabular}{ll}
\hline & $\begin{array}{l}\text { Unstandardized } \\
\text { Residul }\end{array}$ \\
\hline $\mathrm{N}$ & 100 \\
Kolmogrov-Smirnov Z &, 553 \\
Asymp. Sig. (2-tailed) &, 919
\end{tabular}

Sumber: Data diolah, 2021

Berdasarkan Tabel 7. Hasil uji normalitas berdasarkan pada uji KolmogrovSmirnov, dengan ketentuan jika signifikasi yang diperoleh $>\alpha$ (taraf signifikasi $\alpha=$ $0,05)$, maka sampel berasal dari populasi berdistribusi normal, dan jika signifikansi yang diperoleh $<\alpha$, sampel tersebut bukan dari populasi yang berdistribusi normal. Maka, data kualitas produk $\left(\mathrm{X}_{1}\right)$, kualitas pelayanan $\left(\mathrm{X}_{2}\right)$, dan keputusan pengguna $(\mathrm{Y})$ mendapatkan hasil dari Asymp. Sig (2-tailed) sebesar 0,919 yang artinya data tersebut memiliki hasil sampel yang berdistribusi normal, karena nilai signifikasi lebih dari 0,05 .

Tabel 8.

Hasil Uji Multikolinaeritas

\begin{tabular}{llll}
\hline \multirow{2}{*}{ Model } & & \multicolumn{2}{c}{ Collinearity Statistics } \\
\cline { 3 - 4 } & & Tolerance & VIF \\
\hline \multirow{2}{*}{1} & Kualitas Produk &, 631 & 1,583 \\
& Kualitas Pelayanan &, 632 & 1,583 \\
\hline
\end{tabular}

Sumber: Data diolah, 2021
Berdasarkan Tabel 8. Hasil uji multikolinaeritas berdasarkan pada ketentuan jika nilai nilai tolerance $>0,10$ dan nilai VIF $<10$ maka, data tersebut memiliki sifat Nonmiltikolinearitas yang artinya tidak terjadi hubungan antar variabel independentnya. Maka, data tersebut dapat diketahui bahwa pada variabel kualitas produk $\left(\mathrm{X}_{1}\right)$ dan kualitas pelayanan $\left(\mathrm{X}_{2}\right)$ memiliki masingmasing nilai tolerance sebesar 0,631 >0,10 dan nilai VIF sebesar $1,583<10$, artinya penelitian ini tidak terjadi hubungan antar variabel independennya atau NonMultikolinearitas.

Hasil uji heteroksiditas berdasarkan grafik scatterplot menunjukkan hasil titiktitik berada di atas titik-titik nol dan dibawah titik nol sumbu Y, distribusi titik-titik data tidak akan membentuk pola bergelombang, pertama melebar kemudian menyempit, sebaran titik tidak akan membentuk pola. Dengan demikian, dapat disimpulkan bahwa tidak ada masalah heteroskedastistas.

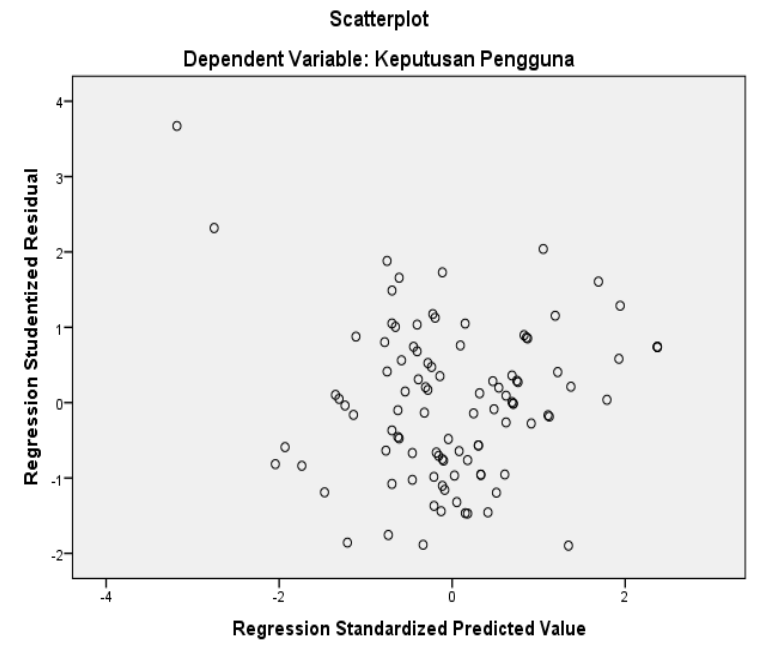

Sumber : Data diolah, 2021

Gambar 1. Hasil Uji Heteroskedastisitas 
Tabel 9.

Uji Analisis Regresi Linear Berganda

\begin{tabular}{lll}
\hline Model & & \multicolumn{1}{c}{ B } \\
\hline \multirow{3}{*}{1} & (Constant) & 4,273 \\
& Kualitas Produk &, 545 \\
& Kualitas Pelayanan &, 247 \\
\hline
\end{tabular}

Sumber : Data diolah, 2021

Berdasarkan Tabel 9. Persamaan analisis regresi linear berganda sebagai berikut:

$Y=4,273+0,545 X_{1}+0,247 X_{2}+e$

Dari hasil koefisien variabel-variabel bebas terlihat bahwa bernilai positif. Hal ini dapat berarti memiliki arah perubahan yang searah dengan variabel terikat. Koefisien variabel kualitas produk sebesar 0,545 sedangkan variabel kualitas pelayanan sebesar 0,247. Dengan demikian dapat ditarik kesimpulan bahwa faktor yang paling dominan yang mempengaruhi keputusan pengguna adalah kualitas produk.

Tabel 10.

Uji Analisis Korelasi Berganda

\begin{tabular}{llll}
\hline Modal & $\mathrm{R}$ & $\mathrm{R}$ Square & $\begin{array}{l}\text { Adjusted } \\
\text { R square }\end{array}$ \\
\hline 1 &, $785^{\mathrm{a}}$ &, 617 &, 609 \\
\hline
\end{tabular}

Sumber: Data diolah, 2021

Berdasarkan Tabel 10. Hasil uji koefisien determinasi $\left(\mathrm{R}^{2}\right)$ diperoleh nilai koefisien determinasi atau adjusted $\mathrm{R}$ square adalah sebesar 0,609 atau sama dengan $60,9 \%$ yang artinya bahwa kualitas produk dan kualitas pelayaan memiliki kemampuan dalam mempengaruhi keputusan pengguna adalah sebesar $60,9 \%$ dan sisanya $39,1 \%$ dijelaskan dan dipengaruhi oleh faktor lain yang tidak dimasukkan dalam penelitian.
Tabel 11.

Hasil Uji Parsial (Uji t)

\begin{tabular}{llcc}
\hline Model & & $\mathrm{t}$ & Sig. \\
\hline \multirow{3}{*}{1} & (Constant) & 2,588 &, 011 \\
& Kualitas Produk & 5,995 &, 000 \\
& Kualitas Pelayanan & 5,071 &, 000
\end{tabular}

Sumber : Data diolah, 2021

Berdasarkan Tabel 11. Hasil uji parsial (uji t) dengan tingkat signifikan $(\alpha)=$ $5 \%(0,05)$, jumlah data $(\mathrm{N}) 100$, dan variabel independen $(\mathrm{K})$ 2, maka nilai degree of freedom $(\mathrm{df})=(\mathrm{n}-2)=100-2=98$ di peroleh $\mathrm{t}_{\text {Tabel }}=1,660$. Maka dapat dibuat kesimpulan menerima atau menolak $\mathrm{H}_{0}$, sebagai berikut: Kualitas Produk $\left(\mathrm{X}_{1}\right)$, berdasarkan hasil uji hipotesis t, Kualitas produk memiliki thitung $5,995>t_{\text {Tabel }} 1,660$ dengan nilai sig $0,000<$ 0,05. Sehingga dapat disimpulkan bahwa $\mathrm{H}_{0}$ ditolak dan $\mathrm{H}_{1}$ diterima, yang artinya bahwa Kualitas Produk $\left(\mathrm{X}_{1}\right)$ berpengaruh terhadap Keputusan Pengguna (Y).

Kualitas Pelayanan $\left(\mathrm{X}_{2}\right)$, berdasarkan hasil uji hipotesis $t$, kualitas pelayanan memiliki $t_{\text {hitung }} 5,071>\mathrm{t}_{\text {Tabel }} 1,660$ dengan nilai sig $0,000<0,05$. Dengan demikian dapat disimpulkan bahwa $\mathrm{H}_{0}$ ditolak dan $\mathrm{H}_{1}$ diterima, yang artinya Kualitas Pelayanan $\left(\mathrm{X}_{2}\right)$ berpengaruh terhadap Keputusan Pengguna (Y).

Tabel 12.

Hasil Uji Simultan (Uji F)

\begin{tabular}{llll}
\hline Model & & F & Sig. \\
\hline 1 & Regression & 1257,209 &, 000 \\
& Residual & 781,751 & \\
& Total & 2038,960 & \\
\hline
\end{tabular}

Sumber : Data diolah, 2021 
Berdasarkan Tabel 12. Hasil uji simultan (uji f) dengan tingkat sigifikan $(\alpha)=$ $5 \%(0,05)$, jumlah data $(\mathrm{N}) 100$, dan variabel independen $(\mathrm{K})$ 2, maka nilai degree of freedom $(\mathrm{df})=\mathrm{n}-2=100-2=98$, diperoleh $\mathrm{f}_{\text {Tabel }}=3,09$. Maka, dapat diketahui nilai $\mathrm{f}_{\text {hitung }}$ 1257,209 > $\mathrm{f}_{\text {Tabel }}$ 3,09 dengan nilai sig $0,000<0,05$. Sehingga dapat ditarik kesimpulan bahwa kualitas produk dan kualitas pelayanan berpengaruh terhadap keputusan pengguna.

Hasil uji hipotesis pengaruh kualitas produk terhadap kualitas pengguna diketahui bahwa $\mathrm{H}_{0}$ ditolak dan $\mathrm{H}_{1}$ diterima yang artinya kualitas produk berpengaruh terhadap keputusan pengguna IndiHome di Karawang. Kualitas produk merupakan proses evaluasi secara keseluruhan kepada pelanggan atas perbaikan kinerja suatu barang atau jasa (Mowen \& Minor, 2012). Hal ini menjelaskan bagaimana kualitas produk dapat mempengaruhi keputusan pembelian atau keputusan untuk menggunakan suatu produk atau jasa tertentu. Hasil penelitian ini sejalan dengan hasil penelitian Daulay (2017) dimana penelitian menunjukkan bahwa kualitas produk berpengaruh positif signifikan terhadap keputusan pembelian.

Hasil uji hipotesis pengaruh kualitas pelayanan terhadap keputusan pengguna diketahui bahwa $\mathrm{H}_{0}$ ditolak dan $\mathrm{H}_{1}$ diterima, yang artinya kualitas pelayanan berpengaruh terhadap keputusan pengguna IndiHome di Karawang. Kualitas pelayanan jasa adalah perbandingan antara harapan konsumen dengan kinerja kualitas pelayanan (Olsen \& Wyckoff dalam Yamit, 2013:22). Jadi, semakin baik kualitas produknya, semakin tinggi pula peluang konsumen untuk mengambil keputusan penggunaan (Kotler \& Armstong, 2018). Hasil penelitian ini sejalan dengan hasil penelitian Weenas (2013) dimana penelitian menunjukkan bahwa kualitas pelayanan berpengaruh positif dan signifikan terhadap keputusan pembelian.

\section{SIMPULAN DAN SARAN}

Berdasarkan latar belakang masalah serta analisis data yang telah dilakukan maka, dapat disimpulkan dari penelitian ini bahwa kualitas produk berpengaruh positif dan signifikan terhadap keputusan pengguna IndiHome di Karawang, hal tersebut menunjukkan bahwa semakin baik kualitas produk yang diberkan oleh perusahaan maka keputusan untuk menggunakan IndiHome akan semakin besar dan kualitas pelayanan berpengaruh positif dan signifikan terhadap keputusan pengguna IndiHome di Karawang, hal tersebut menunjukkan bahwa semakin kualitas pelayanan ditingkatkan dan lebih diperhatikan maka, keputusan untuk menggunakan IndiHome akan semakin meningkat.

Berdasarkan hasil dan kesimpulan penelitian, maka adapun saran-saran yang ditemukan, yaitu: 1) dalam upaya peningkatan produk, maka disarankan agar IndiHome Karawang dapat memperhatikan kualitas produknya seperti lebih memperhatikan jaringan internet secara lebih optimal untuk memperkecil keluhan pengguna setiap pemakaiannya. 2) dalam upaya peningkatan pelayanan, maka disarankan agar IndiHome Karawang dapat lebih di perhatikan mengenai ketepatan waktu dalam menjawab kebutuhan tiap pengguna 
IndiHome. 3) dalam upaya peningkatan pelanggan, maka disarankan agar IndiHome Karawang selalu melakukan evaluasi perbaikan produk dan pelayanan dari tiap saran dan kritikan pelanggan. 4) bagi peneliti selanjutnya, diharapkan dapat meneliti di tahun berikutnya berdasarkan data terbaru dan dapat meneliti objek penelitian lain terutama objek produk fixed broadband di Karawang.

\section{REFERENSI}

Abdul, M., Yunus, M., \& Darsono, N. (2017). Pengaruh Kualitas Pelayanan dan Citra Perusahaan terhadap Loyalitas Pelanggan Indihome PT. Telkom Indonesia di Banda Aceh Dengan Kepuasan dan Kepercayaan Pelanggan sebagai Variabel Mediasi. Jurnal Manajemen Dan Inovasi, 8(3), 37-51. http://jurnal.unsyiah.ac.id/JInoMan/article/vie w/9342

APJII. (2018). Survei APJII yang Ditunggutunggu,Penetrasi Internet Indonesia 2018. Retrieved from https://apjii.or.id/content/read/ 104/418/BULETIN-APJII-EDISI-40---Mei2019

Arief, M. (2020). Pemasaran Jasa dan Kualitas Pelayanan (Bagaimana mengelola kualitas pelayanan agar memuaskan pelanggan). Malang: Bayumedia Publishing.

Daulay, N. (2017). Pengaruh Kualitas Produk Dan Kualitas Layanan Terhadap Keputusan Pembeli. (Skripsi). Medan: Universitas Islam Negeri Sumatera Utara

Eka, D., Hamdaini, Y., \& Karim, S. (2019). Kualitas Pelayanan Fakultas Ekonomi Universitas Sriwijaya. Jurnal Manajemen Dan Bisnis Sriwijaya, $\quad$ 16(2), 89-98. https://doi.org/10.29259/jmbs.v16i2.6948

Kodu, S. (2013). Harga, Kualitas Produk Dan Kualitas Pelayanan Pengaruhnya Terhadap Keputusan Pembelian Mobil Toyota Avanza. Jurnal Riset Ekonomi, Manajemen, Bisnis Dan Akuntansi, 1(3), 1251-1259. https://doi.org/10.1002/pola. 21914

Kotler, P., \& Armstrong, G. (2018). Principle of Marketing. United Kingdom: Pearson Education Limited.

Kotler, P., \& Keller, K. L (2012). Manajemen
Pemasaran. Jakarta: Erlangga

Kristo, F. Y. (2020). Layanan Zoom di IndiHome Gangguan, Ini Jawaban Telkom. Retrieved fromwebsite:https://inet.detik.com/telecommu nication/d-5211682/layanan-zoom-di indihome-gangguan-ini-jawaban-telkom. (Diakses 13 Oktober 2020)

Mediakonsumen.com. (2020). Pelayanan Telkom Indihome sangat tidak bersahabat. Retrieved from https://mediakonsumen.com/2020/04/23 /surat-pembaca/pelayanan-telkom-indihomesangat-tidak-bersahabat-dengan-konsumen

Mertayasa, P., \& Giantari, I. G. A. K. (2020). Pengaruh Kualitas Produk Dan Citra Merek Terhadap Kepuasan Pelanggan Dan Dampaknya Terhadap Komunikasi Word of Mouth. Buletin Studi Ekonomi, 25(1), 1-21 https://doi.org/10.24843/bse.2020.v25.i01.p01

Mowen, J. C., \& Minor, M. (2012). Perilaku Konsumen (Jilid Kedua). Jakarta: Erlangga

Nasution, H., Maksum, C., \& Derriawan. (2017). Pengaruh kualitas pelayanan dan harga terhadap keputusan pembelian customer serta dampaknya pada kepuasan pelanggan (Studi kasus: Maskapai PT . Lion Air Jakarta). Ekobisman: Jurnal Ekonomi Bisnis Manajemen, 3(2), 175-191. http://journal.univpancasila.ac.id/index.php/ek obisman/article/view/875

Pertiwi, W. K. (2020). Layanan IndiHome Dilaporkan Mengalami Gangguan. Retrieved from website: https://tekno.kompas.com/read/2020/ 07/17/10050097/layanan-indihomedilaporkanmengalami-gangguan. (Diakses 17 juli 2020)

Purnamasari, I. G. . Y. (2015). Pengaruh Kualitas Produk Dan Harga Terhadap Kepuasan Konsumen Produk M2 Fashion Online Di Singaraja Tahun 2015. Jurnal Jurusan Pendidikan Ekonomi (JJP), 5(1), 1-12. https://ejournal.undiksha.ac.id/index.php/JJPE /article/view/6353

Raka, M. (2020). Pelanggan IndiHome Karawang Naik 100 Persen. Retrieved from website: https://radarkarawang.id/metropolis/pelangga n-indihome-karawang-naik-100-persen/ (Diakses 9 juli 2020)

Rumondor, P., Tumbel, A., \& Ogi, I. (2017). Pengaruh Kualitas Produk, Harga, Dan Word of Mouth Terhadap Keputusan Pembelian Pada Rumah Kopi Dan Mie Toronata Di Kawangkoan. Jurnal Riset Ekonomi, Manajemen, Bisnis Dan Akuntansi, 5(2), 1102-1112. https://doi.org/10.35794/emba.v5i2.16084 
Pengaruh Kualitas Produk dan Kualitas Pelayanan Terhadap... Mega Naliyah Syahfitri \& Danang Kusnanto

Sugiyono. (2014). Metode Penelitian Kuantitatif Kualitatif Dan $R \& D$. Bandung: Alfabeta.

Sunyoto, D. (2012). Konsep Dasar Riset Pemasaran dan Perilaku Konsumen. Yogyakarta: CAPS (Center for Academic Publishing Service)

TelkomIndonesia. (2019). Laporan Tahunan 2019 Telkom Indonesia: Committed to Sustainable Growth and Better Profitabilty in Capturing Digital Opportunities. Retrieved from https://telkom.co.id/data/lampiran/159144785 2142_AR Telkom 2019_INDO_FINAL.pdf

Weenas, J. (2013). Kualitas Produk, Harga, Promosi Dan Kualitas Pelayanan Pengaruhnya Terhadap Keputusan Pembelian Spring Bed Comforta. Jurnal Riset Ekonomi, Manajemen, Bisnis Dan Akuntansi, 1(4), 607-618. https://doi.org/10.35794/emba.v1i4.2741

Yamit, Z. (2013). Manajemen Kualitas Produk dan Jasa. Yogyakarta: Ekonisia. 